\title{
Negotiating with Indigenous Peoples: Land Area Acquisition for the Fulkaxó Reserve in Brazil
}

Silvana Sartori, Marco Jantsch, Dr. Murillo de Oliveira Dias ${ }^{*}$, Dr. Rodrigo Navarro

Fundação Getulio Vargas, Brazil

DOI: $10.36348 /$ sjef.2020.v04i09.006

| Received: 07.09.2020 | Accepted: 15.09.2020 | Published: 17.09.2020

*Corresponding author: Murillo de Oliveira Dias

\section{Abstract}

The purpose of this study is to present a negotiation case for the acquisition of a land area from the Fulkaxó, indigenous people of Brazil, aiming at establishing a reserved space for families of the Fulkaxó Peoples (Fulniô/Kariri-Xocó/Xocós Ethnicgroups), in properties located in the municipalities of Neópolis and Pacatuba, State of Sergipe, according to the court decision in the case of Public Civil Action n. 0003667-09.2012.4.05.8500, in proceedings before the First Federal Court of the Judicial Section of Sergipe. The negotiation for land acquisition endured for thirteen years, completed on 18 August 2020. The research aims to provide scholars, business managers, and decision-makers with a new perspective on the negotiation process involving indigenous peoples and the Brazilian Federal Government. Case analysis and discussion compile the present work.

Keywords: Negotiating, Fulkaxó Peoples, Case analysis.

Copyright @ 2020: This is an open-access article distributed under the terms of the Creative Commons Attribution license which permits unrestricted use, distribution, and reproduction in any medium for non-commercial use (NonCommercial, or CC-BY-NC) provided the original author and source are credited.

\section{INTRODUCTION}

First inhabitants of Brazil, long before the arrival of the first Portuguese conquerors, led by the Portuguese Pedro Álvares Cabral in 1500, the indigenous tribes and nations gradually gave way to the white man. Its culture, traditions, and population are confined to restricted areas, indigenous reserves, increasingly smaller, in Brazil.

Indigenous peoples in Brazil are considered legally incapable of decision making. Despite the challenging, sometimes conflicting situations faced by the indigenous peoples in Brazil. In this article, we investigated a thirteen-year negotiation involving a tribe of Indians from the northeastern State of Sergipe, and the Brazilian Federal Government, as the unit of analysis of the present descriptive, single case study [1].

The subject is currently being processed within the framework of FUNAI National Indian Foundation (Fundação Nacional do Índio) General Coordination of Land Affairs (CGAF/FUNAI/MJSP), having its basis of work from the studies carried out by the technical group of Ordinance n. 1.104/Pres/Funai, of 08.27.2018, in which the report of the selected area with about 796 hectares was presented, formed by three adjacent properties called Fazenda Cadoz de Cima (553ha),
Fazenda Cadoz de Baixo (199ha), and the property of the Government of the State of Sergipe (44ha).

From 1500 to date, the indigenous population has severely decreased, according to Figure-1:

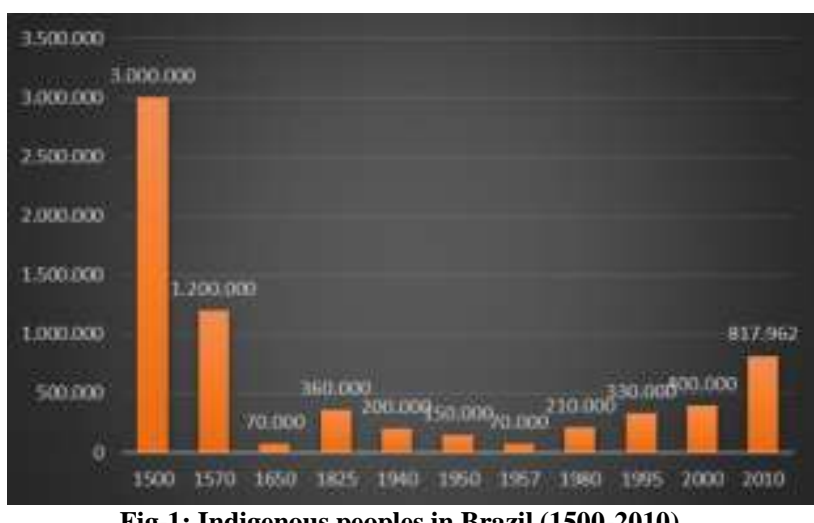

Fig-1: Indigenous peoples in Brazil (1500-2010) Source: FUNAI (2020)

Observe in Figure-1, the last census that the indigenous population was reduced to 2.7 percent the original number of inhabitants, 502,783 live in the rural area, and 315,180 live in Brazilian urban areas. Approximately 274 indigenous languages are spoken in Brazil, from which only 17.5 percent speak Brazilian Portuguese [12]. 
Figure 2 illustrates the indigenous peoples' distribution amongst the five Brazilian regions:

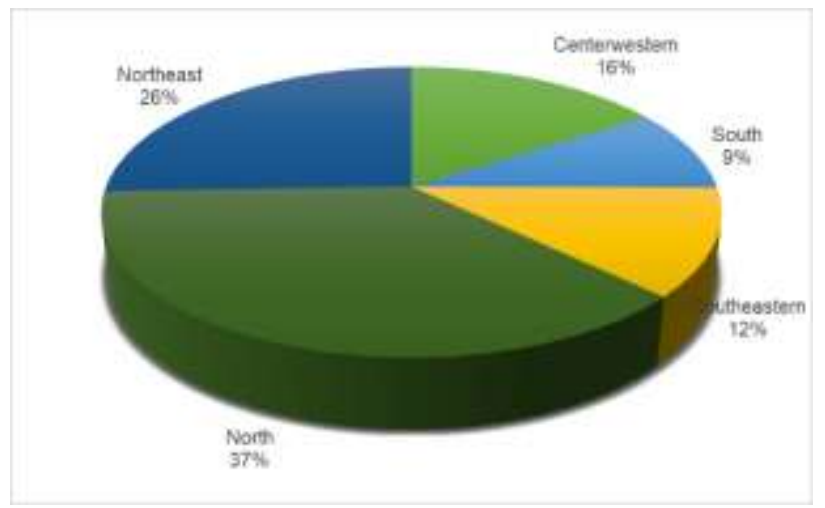

Fig-2: Indigenous peoples' distribution Source: FUNAI, 2020

Observe in Figure-2 the highest concentration of indigenous population within the North region (37 percent), while the northeast region, where the negotiation took place, is responsible for 26 percent of the entire populational distribution.

Therefore, FUNAI needs to acquire these areas and pass them on to the enjoyment of that indigenous community, thus calling the community's full ownership.
The first unsuccessful attempt was to purchase directly from the area's owner in question since the anthropological study identified it as ideal to meet the Indigenous Community's culture's nuances on screen.

Negotiations goals are, sometimes, hard to accomplish due to many factors. In this work, we define negotiation as "a process of communication by which two or more persons seek to advance their interests through joint action [2]." Negotiations have attracted a great deal of scholars' attention over the past decades [3-10]. The present case is also investigated as a buyerseller negotiation [11]. Additionally, we followed Dias' Four-Type Negotiation Matrix to analyze the case [3]. Next, we present the research methods.

\section{RESEARCH METHODS}

Qualitative research encourages researchers to get into the field of study to grasp new insights into the negotiation process. In this research, we adopted the interpretive approach, inductive reasoning, combining extensive archival research with the descriptive, single case study, in which land acquisition negotiation is the unit of analysis [1].

We also applied the Four-Type Negotiation Matrix to analyze the case, a two-dimensional model for addressing negotiation processes. It encompasses the number of parties involved, and the number of issues negotiated, as illustrated in Figure-3:

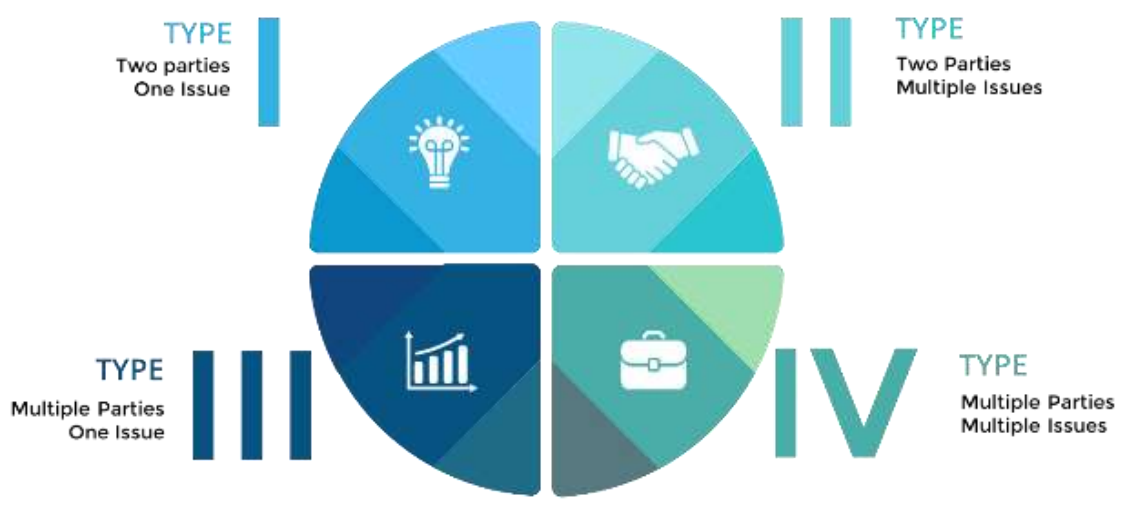

Fig 3: The Four-Type Negotiation Matrix

Source: Dias, 2020 Reprinted under permission

The advantages of using such a model are better to understand the nature of the negotiation at hand. In the next section, we describe the negotiation case.

\section{BACKGROUND}

First, to support the negotiations, we sought as many information as possible from the following procedures:

i. In the case of the properties Fazendas Cadoz de Cima and Cadoz de Baixo, owned by Mr.
José Roberto de Barros Mello, searches were carried out in the land database collection.

ii. The Land Management System -SIGEF by the technology sector of this Foundation, to better characterize the cartographic location of these and consulting the Registry office of Pacatuba to obtain an updated copy of the Certificate of Content of registrations n. 524 and 285 (Oficio

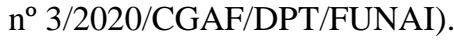


iii. The previous contact by phone with the property owner to start dealings on the disposal of the areas also occurred.

iv. Other points established were to contact the INCRA Superintendence in Aracaju, to provide information perhaps existing in that municipality about the properties, and the approximate value per hectare in the region covered by the chosen area (Letters No. 1 and 4/2020/CGAF/DPT/FUNAI).

Concerning the area that belongs to the State of Sergipe, a videoconference was held with the Secretary of State for Agriculture, Agrarian Development, and Fisheries of the State of Sergipe, Mr. André Luiz Ferreira.

The presentation of an updated report on the land situation of the property was forwarded, and the cartographic data of the georeferencing of the area with the map and descriptive memorial, the notary documentation, subject reported by The Official No. 5/2020/CGAF/DPT/FUNAI.

The Brazilian Forest Service was also asked to report a Rural Environmental Registry (CAR) on the question.

Therefore, all administrative arrangements regarding the COVID-19 pandemic were followed, which imposed restrictions on the execution of various activities and actions that significantly impaired compliance with the 120-day legal deadline for the dispute's conclusion.

\section{THE NEGOTIATION PROCESS}

On 11 August 2020, the CGAF/FUNAI servers moved to Pacatuba/SE, where the properties are located for their purchase negotiations. There was a meeting with the son of the owner of The Cadoz Farms, Mr. José Roberto de Barros Mello Filho, in the house, which is located in The Cadoz de Baixo Farm, which welcomed the indigenous community to their lands since the beginning of this process, information confirmed by the Indians, who claimed to be a friendly and respectful atmosphere in the region.

At this moment, it was discovered a piece of important information in this process, the death of $\mathrm{Mr}$. José Roberto de Barros Mello, the owner of the land areas, and that weighs on them a formal sharing unsuccess.

The General Coordinator informed Mr. José Roberto Filho (self-styled owner of the Farms - since in the will he is the sole beneficiary in relation to these properties, a point of discussion between the other heirs and reason for non-agreement) about the urgency of concluding this transaction as soon as possible, given the budget constraints of the Agency and since the period of financial reversal for the 2020 Budget ends in September of the current. It was also reported that INCRA/MAPA should come to evaluate the property, with a view to calculating the fair and correct value. Mr. José Roberto claimed not to be satisfied with the estimated value (based on the Land Reference Price Sheets (PPR) of INCRA SR 23), but stated that he wanted to resolve this situation, collaborating with whatever it takes.

On occasion, Mr. José Roberto Filho emphasized the need to obtain georeferencing of the property, since the area has not yet been georeferenced, and this procedure is imperative for the completion of the purchasing process.

During the negotiations, Mr. José Roberto Filho was also questioned about the Rural Environmental Registers (CARs) that are overlapping Cadoz de Cima, according to the Brazilian Forest Service relationship. He reported that the only one he knows of is referring to Mr. Cicero, but does not know if he remains in place.

The following day, 12/08/2020, in Aracajú/SE, CGAF/FUNAI met with the Secretary of Agriculture of the State of Sergipe (André Luiz B. Ferreira), as well as Mr. Roberto Lucas S. Freire (Superintendent of INCRA/MAPA in Sergipe) and Victor Alexandre S. Santos, also of INCRA/MAPA.

The purpose of the meeting was to deal with the middle's property, owned by the State of Sergipe, where the information that is currently occupied by landless residents emerges. All made themselves available to collaborate with the regularization of the area to the extent of their competences. The Secretary of Agriculture said that there would be no obstacle in ceding the property to the composition of RI Fulkaxó, through purchase by Funai, after expertise to calculate its value by INCRA / MAPA. He also reported that the State of Sergipe could relocate landless residents, who are currently installed in the area, elsewhere, with a view to the constitution of an agricultural colony, with recognition by INCRA/MAPA, in better conditions than they are currently.

As referrals from this meeting, the State of Sergipe will register the landless families occupying the middle area in the brevity that the case requires, avoiding new opportunistic actors' entry. They could perhaps benefit from the assignment of new areas to these families in the regularization of RI FULKAXÓ. After this step, THE INCRA / MAPA will forward agrarian experts, aiming to prepare an expert report of the evaluation of the Cadoz de Cima Farm and the middle (belonging to the government of the State of Sergipe). For FUNAI, it was left to clarify with Mr. José Roberto de Barros Mello Filho about the regularization of the property $\mathrm{Cadoz}$ de Cima and 
Cadoz de Baixo in the bulge of the Estate of José Roberto de Barros Mello.

\section{THE CASE TURNAROUND}

Even with all precautions taken, some surprises came across the negotiation:

i. The death of Mr. José Roberto de Barros Mello, which occurred in 2013, and the fact that a formal sharing agreement, which has not yet reached consensus between the parties, has yet to be found, for the definitive outcome of the farms involved in the process of composition of RI Fulkaxó/SE, a situation is even before the conclusion of the study conducted by FUNAI;

ii. The intention of Mr. José Roberto de Barros Mello Filho to get away only from The Cadoz de Cima Farm;

iii. (iii) The overlap of 4 areas in the CAR (Rural Environmental Registry of the Brazilian Forest Service) on behalf of other owners, on the area of Fazenda Cadoz de Cima;

iv. The non-georeferencing of the areas related to the Cadoz de Cima and $\mathrm{Cadoz}$ de Baixo Farms. (Indispensable for the completion of the purchasing process);

v. The occupation of the Sergipe state area by landless families;

\section{CURRENT STATUS}

The owner's passing away is the biggest obstacle at the moment. The solution to the deadlock includes a series of notary measures, difficult to address, due to the lack of consensus between the parties.

Regarding the sale values of the Cadoz de Cima property (553ha), the would-be owner yearn for a value close to $R \$ 5$ million for the area, and the preliminary values of the INCRA/MAPA tables for that region total about $\mathrm{R} \$ 2.5$ million (which in turn are in line with the budget available by FUNAI for such acquisition).

Regarding the area belonging to the State of Sergipe (44ha), this seems to be the easiest solution, provided that FUNAI acquires the area at the right price (the State of Sergipe agrees with the evaluation base of INCRA/MAPA). This price will be set after the evaluation of the property by INCRA /MAPA. The State of Sergipe has already taken responsibility for the landless removal and settlement that occupy today.

\section{CASE ANALYSIS}

First, the case is a Type IV negotiation (multiple parties, multiple issues), according to Dias [1]. Some alternatives emerge for a final agreement to complete the process of acquiring these properties:

i. As for the estate of Mr. José Roberto de Barros Mello and the need to overshare the properties
Fazenda Cadoz de Cima and Fazenda Cadoz de Baixo. Funai, concerning Fazenda Cadoz de Cima (553ha), since there is no consensus on the formal sharing, can propose to the Court the deposit of the amount indicated by the evaluation of INCRA / MAPA in judicial account, on behalf of the estate, with subsequent admission of ownership of the property on behalf of the Union, leaving room for the discussion of values within the judicial, in the broad right of the adversary.

ii. Still on the Cadoz de Cima and Cadoz de Baixo Farms, weigh on them a Presidential Decree of Expropriation by Social Interest, and in turn also propose to the Court the deposit of the value indicated by the evaluation of INCRA / MAPA in judicial account, on behalf of the owners, with subsequent admission of ownership of the property on behalf of the Union, leaving room for the discussion of values within the judicial, in the broad right of the adversary.

iii. Regarding the area belonging to the State of Sergipe (44ha), it remains only to conclude the evaluation report by INCRA/MAPA and propose the acquisition to the State, which has already agreed with the table of values employed.

iv. Due to the absence of momentary budgetary and financial availability on the part of FUNAI and the lack of interest in the sale of Fazenda Cadoz de Baixo (199ha) at this time by the alleged owner, as well as such a situation generates a cordial and friendly atmosphere among the indigenous peoples who are already on-site, the process will remain overdue until the State Agency can acquire such property. This factor depends on the opinion of the Federal Court and Public Prosecutor's Office (MPF).

We highlight the evolution of the negotiation based on the asymmetry of information. There was the need for a face-to-face meeting given the complexity of the data that were emerging from pre-negotiation research and, especially, the difficulty of the alleged owner of the farms in dealing with new technologies. As well as one cannot despise that by the fact of being a person of a certain age, bring much present the most traditional trading model, that is, eye to eye and finished with a handshake (which in times of pandemic was replaced by a touch of elbows).

Because it is several subjects and different issues, but with a common purpose, we can say that in the case on screen, it was an Integrative Negotiation, whereby its characteristics the two environments were, the competitive and the collaborative. In the case of negotiation with the Government of the State of Sergipe, the collaborative positioning prevailing 
throughout the negotiation process was clearly seen. In turn, the Farms' alleged owner's negotiation process, despite its position to solve the issue, was still seen as a competitive stance, especially about the values proposed preliminary.

Concerning the negotiation with the Government of the State of Sergipe for the acquisition of the area of land owned by him (44ha), we have the Zone of Possible Agreement - ZOPA appearing on top of the values provided in the table of INCRA / MAPA for the evaluation of land in that region, and that body should only complete the evaluation to make up its final price.

In the case of the acquisition of Fazenda Cadoz de Cima (553ha) that the Best Alternative in Case of Non-Agreement (MACNA/BATNA) will be, since there is no consensus on the formal sharing, propose to the Court the deposit of the amount indicated by the evaluation of INCRA / MAPA in judicial account, on behalf of the estate, with subsequent admission of possession of the property on behalf of the Union, leaving room for the discussion of values within the judicial, in the broad right of the adversary, considering the need to complete this acquisition process within the period determined by the 1 st Federal Court of the Judicial Section of Sergipe.

About Fazenda Cadoz de Baixo (199ha) the alternative would be to ask for the agreement of the Federal Court and Public Prosecutor's Office (MPF) to overdo the process of acquisition of this area, based on the absence of momentary budgetary and financial availability on the part of FUNAI and the lack of interest in the sale of Fazenda Cadoz de Baixo (199ha) at this time by the would-be owner, as well as this situation generates a cordial and friendly atmosphere among the indigenous peoples who are already on site.

\section{DISCUSSION}

Considering the legal nuances that govern the process of acquiring land areas for the composition of Indigenous Reserves, one of the main points that hindered the negotiation was the fact that during the studies made for the election of the area, the documentary issue of the area was ignored concerning its property.

This information is fundamental to the right negotiating field and brings legitimacy to the parties involved. In this specific case, it imposed the search for alternatives of non-agreement for the conclusion of the case.

\section{FUTURE RESEARCH}

Future research is encouraged regarding the multicultural aspects of indigenous peoples in Brazil. Also, communication issues between the different tribes and the Brazilian Portuguese speakers, to what extent language barriers impact the negotiation process, should be addressed in future studies.

\section{REFERENCES}

1. Yin, R. (2013) Case Study Research: Design and Methods. Sage Publications, fifth edition.

2. Salacuse, J. (2008). Seven Secrets for Negotiating with Government: How to Deal with Local, State, National, or Foreign Governments - And Come Out Ahead. New York: Amacom.

3. Dias, M. (2020) The Four-Type Negotiation Matrix: A Model for Assessing Negotiation Processes. British Journal of Education, 8(5), 40-57.

4. Raiffa, H. (1982). The Art and the Science of Negotiation: How to Resolve Conflicts and get the Best out of Bargaining. Cambridge, MA: Harvard University Press.

5. Salacuse, J. (2008). Seven Secrets for Negotiating with Government: How to Deal with Local, State, National, or Foreign Governments - And Come Out Ahead. New York: Amacom.

6. Fisher, R., Ury, W., \& Patton, B (Editor). (1981). Getting to Yes: Negotiating an Agreement without Giving in. US: Random House.

7. Sebenius, J. (1992). Negotiation Analysis: A Characterization and Review. Management Science, 38(1), 18-38.

8. Dias, M. (2019). People, Process, and Substance: Current Definitions on Negotiation. International Journal of Commerce and Economics, 1 (3), 1-9.

9. Dias, M. Navarro, R. (2020). Three-Strategy Level Negotiation Model and Four-Type Negotiation Matrix Applied to Brazilian Government Negotiation Cases. British Journal of Management and Marketing Studies, 3(3), 5066. doi: 10.6084/m9.figshare. 1247986

10. Dias, M., Lopes, R., \& Teles, A. (2020). Nonparametric Analysis on Structured Brazilian Business Negotiations. Global Scientific Journal. 8(6), 1511-22.

11. Rinehart, L., \& Page, T. (1992). The Development and Test of a Model of Transaction Negotiation. Journal of Marketing, 56(4), 18-32.

12. FUNAI. (2020). Quem São. Retrieved on 3 September $2020 \quad$ from http://www.funai.gov.br/index.php/indios-nobrasil/quem-sao

13. Navarro, R. (2020). The Strategic Government Relations Handbook. Amazon. 